\title{
Optimization Model for the Selection of the Community Risk Registration Indicator and Its Application in Fire Risk*
}

\author{
SU Jie \\ Central University of Finance and Economics \\ Beijing, China
}

\begin{abstract}
According to the reality and requirement of our country's community risk registration, this paper puts forward four principles for the selection of community risk registration indicator and then designs the evaluation "goodness" for evaluating the community risk registration indicator. On this basis, this paper constructs a multi-objective programming to select a comprehensive evaluation indicator system. Finally, this paper takes the community fire risk register as an example and couples with experts grading method to construct a scientific and feasible community fire risk registration form.
\end{abstract}

Keywords—fire risk; risk registration; evaluation "goodness"

\section{INTRODUCTION}

With the increasing of complexity and frequency of occurrence of the social harmfulness, risk management has been an important part of the comprehensive social management work. As a significant prerequisite and segment of risk management, risk registration plays a role of connecting between the preceding and the following in the whole process of risk management. Constructing risk registration system scientifically can help to guide the risk management more effectively.

Foreign Study on risk registration has been relatively mature, for example, London establishes a city risk management system based on the comprehensive risk registration, compiles and releases risk register every year, which enhances the emergency management capability [1-3]. The study of risk registration in our country is accelerating these years, for example, You Zhibin analyzes the main work of the federal government in promoting the construction of risk management[4]; Zhou Yonggen,etc. proposes the construction principle and the implementation advice of the standard system of risk management in cities[5].

This paper put forward four principles for the selection of community risk registration indicator and then designs the evaluation "goodness" for evaluating the community risk registration indicator. On this basis, this paper constructs a multi-objective programming to select a comprehensive evaluation indicator system. Finally, this paper takes the community fire risk register as an example and coupled with experts grading method to construct a scientific and feasible community fire risk registration form.

\author{
LIAN Jie \\ Central University of Finance and Economics \\ Beijing, China
}

\section{PRINCIPLES FOR THE SELECTION OF COMMUNITY RISK REGISTRATION INDICATOR}

\section{A. Scientificalness}

Scientificalness means the indicator system can reflect the major aspects of the regional risks comprehensively, as well as the specific content of a particular aspect correctly.

\section{B. Feasibility}

Feasibility means the selected indicator is sure to be acquired and be obtained relevant data, even if the selected indicator is difficult to acquire, it should be able to be reflected from other aspects and eventually be quantified.

\section{Stability}

Stability means the selected indicator is not determined by accident factors, the selected indicator should be regulated by laws and regulations or be mentioned in relevant documents, it must be robustness.

\section{Independence}

Independence means the selected indicator should be oneto-one mapping with the evaluation factor theoretically, there is no one-to-many or many-to-one relationship between the selected indicator and the evaluation factor.

\section{A Multi-obJective Programming FOR the SELECTION OF COMMUNITY RISK REGISTRATION INDICATOR BASED ON EVALUATION “GOODNESS”}

A. Evaluation "goodness" indicator and calculation method

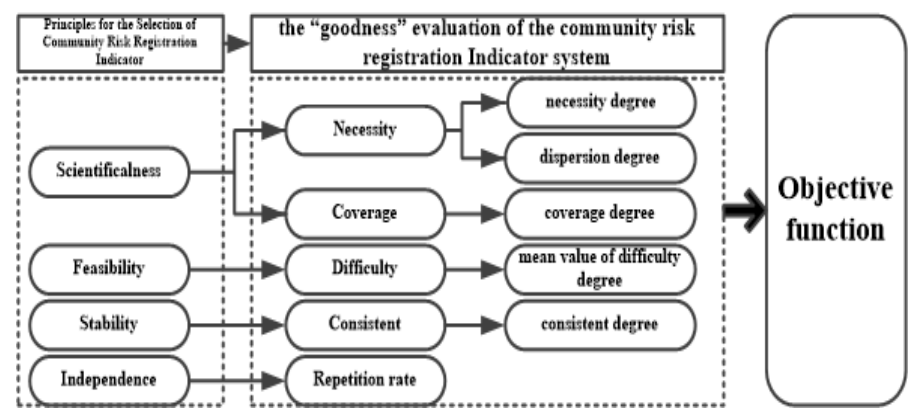

Major project funded by the National Natural Science Foundation of China (No. 91324203). 
1) Necessity of indicator system.

Necessity is measured by necessity degree and dispersion degree.

Necessity degree is evaluated by experts, the specific indicator should be evaluated by each expert and then calculate the mean value of evaluation of all experts. The higher the necessity degree is, the higher the necessity of indicator is.

If there are $m$ indicator in an indicator system and $q$ experts, and the necessity degree of indicator is divided into 5 levels, that is $j=(1,2,3,4,5)$ means the necessity degree of indicator is "extremely high", "very high", "high", "moderate", "low", thus, the formula of the necessity degree can be described as follows:

$$
\begin{aligned}
& F_{i}=\frac{1}{q} \sum_{j=1}^{5} E_{j} n_{i j} \\
& F=\frac{1}{m} \sum_{i=1}^{m} F_{i}=\frac{1}{m q} \sum_{i=1}^{m} \sum_{j=1}^{5} E_{j} n_{i j}
\end{aligned}
$$

$F_{i}$ is the mean value of the necessity degree of indicator $i$ evaluated by $q$ experts; $E_{j}$ is the value of level $j$ of indicator $i ; n_{i j}$ is the number of experts who evaluate indicator $i$ as level $j ; F$ is the overall necessity degree of indicator system.

Dispersion degree is indicated by $D$ and measured by standard error $\delta$. Dispersion degree reflects the degree of experts' opinion when evaluating the necessity of the indicator system. The lower the dispersion degree is, the more consistent the expert's opinion is.

$$
\begin{aligned}
& D_{i}=\delta_{i}=\sqrt{\frac{1}{q-1} \sum_{j=1}^{5} n_{i j}\left(E_{j}-F_{i}\right)^{2}} \\
& D=\sum_{i=1}^{m} D_{i} / m
\end{aligned}
$$

$D_{i}$ is the dispersion degree of indicator $i$ evaluated by $q$ experts, in general, $\delta_{i}>0.63$ means the dispersion degree of indicator $i$ is high and experts' opinion is inconsistent. $D$ is the overall dispersion degree of indicator system.

\section{2) Coverage degree of indicator system}

The coverage degree means whether all the evaluation factors have corresponding evaluation indicators. In this paper, each evaluation factor has at least one corresponding evaluation indicator. Therefore, the coverage degree of the evaluation factors is 1 .

3) Difficulty degree of obtaining the indicator system

The difficulty degree of obtaining the indicator is evaluated by experts and measured by the mean value of the difficulty degree. In general, the difficulty degree has 5 levels whose value are $1 / 2 / 3 / 4 / 5$.
Defining $x_{i}(i=1,2, \cdots, m)$ as follows:

$$
x_{i}=\left\{\begin{array}{l}
1, \text { index } i \text { is choosen } \\
0, \text { index } i \text { is not choosen }
\end{array}\right.
$$

Defining $N_{i}$ as the difficult degree of indicator $i$. So the mean value of the difficulty degree of indicator is:

$$
N=\sum_{i=1}^{m} N_{i} x_{i} / \sum_{i=1}^{m} x_{i}
$$

If the mean value of the difficulty degree of indicator is less than 2 , then we can say indicator $i$ is easy to obtain.

\section{4) Consistent degree of indicator system}

Suppose there are $m$ indicator evaluated by $q$ experts, the score set evaluated by expert $j$ is $X_{j}, X_{j}=\left\{x_{1 j}, x_{2 j}, \cdots, x_{m j}\right\}$.

Taking the mean value of the score set as ideal data set:

$$
t_{i}=\sum_{j=1}^{q} x_{i j} / q
$$

Based on the formula above we can calculate the consistent degree $\rho_{j}$ between each expert's score and the ideal data group:

$$
\begin{aligned}
\rho_{j} & =\frac{\sum_{i=1}^{m}\left(x_{i j}-\overline{x_{i}}\right)\left(t_{i}-\bar{t}\right)}{\sqrt{\sum_{i=1}^{m}\left(x_{i j}-\overline{x_{i}}\right)^{2} \sum_{i=1}^{m}\left(t_{i}-\bar{t}\right)^{2}}}(j=1,2, \cdots, q) \\
\bar{x}_{i} & =\sum_{j=1}^{q} x_{i j} / q, \bar{t}=\sum_{i=1}^{m} t_{i} / m
\end{aligned}
$$

The overall consistent degree of the indicator system is $\rho$ :

$$
\rho=\sum_{j=1}^{m} \rho_{j} / q
$$

In general, $\rho \in(0,0.3)$ means the evaluations of experts are high consistent; $\rho \in(0.3,0.6)$ means the evaluations of experts are moderately consistent; $\rho \in(0.6,1)$ means the evaluations of experts are high inconsistent.

\section{5) Repetition rate of indicator system}

This paper suppose the selected indicator is one-to-one mapping with the evaluation factor, there is no one-to-many or many-to-one relationship between the selected indicator and the evaluation factor. Thus, the repetition rate is 0 . 


\section{B. Multi-objective programming}

In order to select a comprehensive indicators from many factors related to community, this paper uses the objective programming method [10-11].

\section{1) Multi-objective programming}

Because coverage degree and repetition rate have little effect on calculation result, so we choose necessity degree, dispersion degree, mean value of the difficulty degree and overall consistent degree as four objective functions, each objective is maximum necessity degree, minimum dispersion degree, minimum mean value of the difficulty degree and minimum overall consistent degree. So the mathematic model as follow:

$$
\begin{aligned}
& \max F ; \min D ; \min N ; \min \rho \\
& \text { s.t. }\left\{\begin{array}{l}
\frac{1}{m q} \sum_{i=1}^{m} \sum_{j=1}^{5} E_{j} n_{i j} \geq 0.5 \\
\sqrt{\frac{1}{q-1} \sum_{j=1}^{5} n_{i j}\left(E_{j}-F_{i}\right)^{2}} \leq 0.1 \\
\sum_{i=1}^{m} N_{i} x_{i} / \sum_{i=1}^{m} x_{i} \leq 2 \\
\frac{\sum_{j=1}^{q} \sum_{i=1}^{m}\left(x_{i j}-\overline{x_{i}}\right)\left(t_{i}-\bar{t}\right)}{\sqrt{\sum_{i=1}^{m}\left(x_{i j}-\bar{x}_{i}\right)^{2} \sum_{i=1}^{m}\left(t_{i}-\bar{t}\right)^{2}}} \leq 0.3
\end{array}\right.
\end{aligned}
$$

2) Optimizing multi-objective programming

A single objective programming model is obtained by optimizing the above multi-objective programming. In general, the priority of the above evaluation "goodness" is from high to low as follows: necessity degree, mean value of the difficulty degree and overall consistent degree, dispersion degree.

$$
\min \left[p_{1} d_{1}^{-}+p_{2}\left(d_{2}^{+}+d_{3}^{+}\right)+p_{3} d_{4}^{+}\right]
$$

s.t.

$$
\left\{\begin{array}{l}
\frac{1}{m q} \sum_{i=1}^{m} \sum_{j=1}^{5} E_{j} n_{i j}+d_{1}^{-}-d_{1}^{+}=0.5 \\
\sqrt{\frac{1}{q-1} \sum_{j=1}^{5} n_{i j}\left(E_{j}-F_{i}\right)^{2}}+d_{4}^{-}-d_{4}^{+}=0.1 \\
\sum_{i=1}^{m} N_{i} x_{i} / \sum_{i=1}^{m} x_{i} \\
\sum_{j=1}^{q} \sum_{i=1}^{m}\left(x_{i j}-d_{i}^{-}\right)\left(t_{i}-\bar{t}\right) \\
q \sqrt{\sum_{i=1}^{m}\left(x_{i j}-\bar{x}_{i}\right)^{2} \sum_{i=1}^{m}\left(t_{i}-\bar{t}\right)^{2}}
\end{array}\right.
$$

\section{SELECTION OF THE COMMUNITY FIRE RISK REGISTRATION INDICATOR SYSTEM}

\section{A. Experts grading and calculation}

In the analysis of community fire risk, the evaluation factors are divided into five categories which are residential area features, population density, meteorological factors, municipal fire fighting capability and mobile fire fighting capability. Each category has an evaluation indicator system including several different indicators.

Designing a questionnaire and give it to experts to evaluate each indicator, calculating the necessity degree, dispersion degree, difficulty degree and overall consistent degree. The number below in table is the average score evaluated with the above formulas by all the experts.

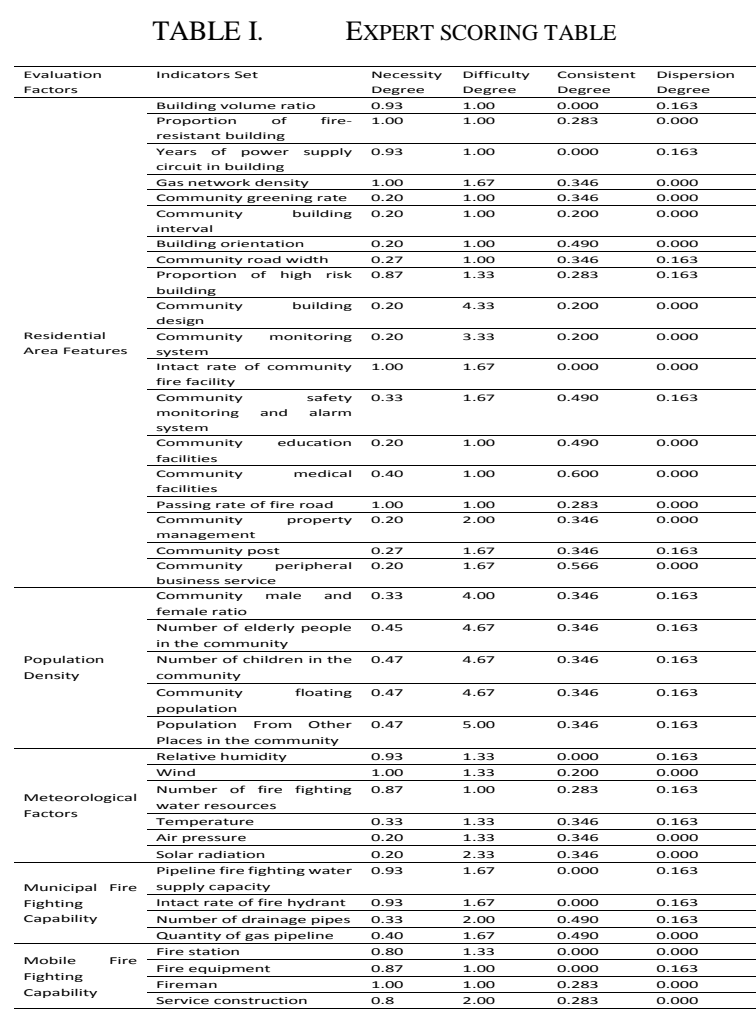

B. Calculating with optimized objective programming

Importing the above value into Excel to calculate the optimal solution. The final result is:

In the evaluation factor "residential area feature", we select "building volume rate", "proportion of fire-resistant building", "years of power supply circuit in building", "gas network density", "proportion of high risk building", "intact rate of community fire facility", "passing rate of fire road" these 7 indicators;

In the evaluation factor "Meteorological Factors", we select "relative humidity", "wind", "number of fire fighting water resources" these 3 indicators; 
In the evaluation factor "municipal fire fighting capacity", we select "pipeline fire fighting water supply capacity", "intact rate of fire hydrant" these 2 indicators;

In the evaluation factor "mobile fire fighting capability", we select "fire station", "fire equipment", "fireman", "service construction" these 4 indicators.

\section{Filling in the community fire risk registration form}

By using objective programming, we select 16 indicators which are closely related to the community fire risk. Actually, the community fire risk is not always evaluated by the experts on the risk management field. Therefore, it is necessary to further simplify the above table and get the risk registration form suitable for the general public. In this paper, some technical terms will be simplified.

TABLE II. CONTENT OF THE COMMUNITY FIRE RISK REGISTRATION FORM

\begin{tabular}{|c|c|c|c|}
\hline Fire risk indicators & Content on fire registration form & Registr & \\
\hline & Building volume ratio & $\begin{array}{l}\text { Community } \\
\text { committee }\end{array}$ & \\
\hline $\begin{array}{l}\text { Proportion of fire- } \\
\text { resistant building }\end{array}$ & Community building structure & $\begin{array}{l}\text { Community } \\
\text { committee }\end{array}$ & neighborhood \\
\hline $\begin{array}{l}\text { Years of power supply } \\
\text { circuit in building }\end{array}$ & Years has been built up & $\begin{array}{l}\text { Community } \\
\text { committee }\end{array}$ & neighborhood \\
\hline Gas network density & Total length of gas pipe & $\begin{array}{l}\text { Community } \\
\text { committee }\end{array}$ & neighborhood \\
\hline High rise building & $\begin{array}{l}\text { Proportion of buildings which are } \\
\text { more than } 7 \text { storey }\end{array}$ & $\begin{array}{l}\text { Community } \\
\text { committee }\end{array}$ & neighbs \\
\hline Public buildings & $\begin{array}{l}\text { Quantity of nearby shopping center / } \\
\text { post office / Kindergarten / Chess } \\
\text { Room / hospital, etc. }\end{array}$ & $\begin{array}{l}\text { Community } \\
\text { committee }\end{array}$ & neighborhood \\
\hline $\begin{array}{l}\begin{array}{l}\text { Intact rate of fire } \\
\text { hydrant }\end{array} \\
\end{array}$ & $\begin{array}{l}\text { Quantity of automatic alarm system } \\
\text { /indoor fire hydrant / Outdoor fire } \\
\text { hydrant }\end{array}$ & $\begin{array}{l}\text { Community } \\
\text { committee }\end{array}$ & neight \\
\hline $\begin{array}{l}\text { Passing rate of fire } \\
\text { road }\end{array}$ & $\begin{array}{l}\text { Fire road width and whether or not } \\
\text { be blocked }\end{array}$ & $\begin{array}{l}\text { Community } \\
\text { committee }\end{array}$ & neighborhood \\
\hline Population density & Population of community registered & $\begin{array}{l}\text { Community } \\
\text { committee }\end{array}$ & neighborhood \\
\hline Relative humidity & Community monthly rainfall situation & $\begin{array}{l}\text { Community } \\
\text { committee }\end{array}$ & neighborho \\
\hline wind & Community monthly wind situation & & o. \\
\hline $\begin{array}{l}\begin{array}{l}\text { Number } \\
\text { fighting } \\
\text { resources }\end{array} \\
\text { of }\end{array} \begin{array}{r}\text { fire } \\
\text { water }\end{array}$ & Number of fire water resources & & \\
\hline $\begin{array}{l}\text { Pipeline fire fighting } \\
\text { water supply capacity }\end{array}$ & Number of fire pipeline & Fire department & \\
\hline Protection area & preparing time consuming & Fire department & \\
\hline $\begin{array}{l}\text { Built-up area } \\
\text { Response time of } \\
\text { adjacent group }\end{array}$ & $\begin{array}{l}\text { Fire station building area } \\
\text { Response time of adjacent group }\end{array}$ & $\begin{array}{l}\text { Fire department } \\
\text { Fire department }\end{array}$ & \\
\hline $\begin{array}{l}\text { Quantity of fire } \\
\text { engine }\end{array}$ & Quantity of fire engine & Fire department & \\
\hline $\begin{array}{l}\text { Quality of fire fighting } \\
\text { equipment }\end{array}$ & Bubble car / water-tank lorry quality & Fire department & \\
\hline $\begin{array}{l}\text { Number of people be } \\
\text { protected by per } \\
\text { fireman }\end{array}$ & $\begin{array}{l}\text { Number of people be protected by } \\
\text { per fireman }\end{array}$ & Fire department & \\
\hline Working years & $\begin{array}{l}\text { Firefighters' number work for more } \\
\text { than } 3 \text { years / } 5 \text { years }\end{array}$ & Fire department & \\
\hline $\begin{array}{l}\text { Guarantee Rate of } \\
\text { training time }\end{array}$ & Firemen's training time every day & Fire department & \\
\hline Plan & $\begin{array}{l}\text { Distribution of key divisions of fire } \\
\text { station }\end{array}$ & Fire department & \\
\hline
\end{tabular}

Through the above table we can finally get the community fire risk registration form as follows:

\begin{tabular}{|c|c|c|}
\hline \multirow{2}{*}{$\begin{array}{l}\text { Community name: } \\
\text { Community area: } \\
\text { km² }^{2}\end{array}$} & \multicolumn{2}{|c|}{$\begin{array}{l}\text { COMMUNITY FIRE RISK REGISTRATION } \\
\text { FORM }\end{array}$} \\
\hline & Building volume ratio: & $\begin{array}{l}\text { Total length of gas pipe: } \\
\mathrm{km}\end{array}$ \\
\hline Number of fire roads: & Fire road width: & $\begin{array}{l}\text { Fire road width and whether or } \\
\text { not be blocked:(1)yes (2)no }\end{array}$ \\
\hline \multicolumn{3}{|c|}{$\begin{array}{l}\text { 1.Community building structure: } \\
\text { (3)wooden structure roof }\end{array}$} \\
\hline \multicolumn{3}{|c|}{$\begin{array}{l}\text { 2. Proportion of building more than seven storey: } \\
30 \% \text {; (4) } 30 \%-10 \% ;(5)<10 \%\end{array}$} \\
\hline \multicolumn{3}{|c|}{ 3. Quantity of nearby shopping center $\quad(1) \geq 3$;(2)2;;(3)1;(4)0; } \\
\hline \multicolumn{3}{|c|}{ 4. Quantity of nearby post office } \\
\hline \multicolumn{3}{|c|}{ 5. Quantity of nearby Kindergarten } \\
\hline \multicolumn{3}{|c|}{ 6. Quantity of nearby chess room } \\
\hline \multicolumn{3}{|c|}{ 7. Quantity of nearby hospital } \\
\hline \multicolumn{3}{|c|}{$\begin{array}{l}\text { 8. Community automatic alarm system (1) } \mathrm{intact} \text {;(2) small part is damaged;(3)large part is } \\
\text { damaged;(4)no automatic alarm system }\end{array}$} \\
\hline \multicolumn{3}{|c|}{$\begin{array}{l}\text { damaged;(4)no automatic alarm system } \\
\text { 9. Community indoor fire hydrant (1) intact; (2)small part is damaged;(3)large part is } \\
\text { damaged; (4) no indoor fire hydrant }\end{array}$} \\
\hline \multicolumn{3}{|c|}{$\begin{array}{l}\text { 10. Community outdoor fire hydrant (1) intact;(2)small part is damaged;(3)large part is } \\
\text { damaged;(4)no outdoor fire hydrant }\end{array}$} \\
\hline \multicolumn{3}{|c|}{$\begin{array}{l}\text { 11. Community rainfall times monthly (1) } \geq 4 \text { times;(2) } 3 \text { times;(3)2 times;(4)1 times;(5) } 0 \\
\text { times; }\end{array}$} \\
\hline
\end{tabular}

Below is filled in by the fire department

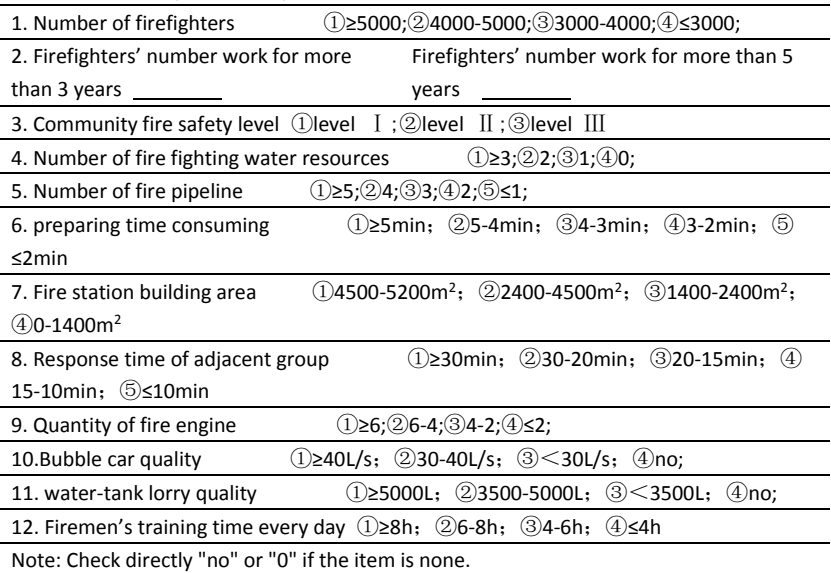

\section{CONCLUSION}

In this paper, we firstly obtain a comprehensive indicator system by using expert grading method and objective programming, and then get a scientific and reasonable risk registration form, which can provide a standard system for the assessment of community fire risk, make the risk assessment quantified, improve the efficiency and effect of risk management, make sure to make the right decisions faced with risk and improve the response capability.

At the same time, the method in this paper provide a reference for the construction of the risk register in other fields.

\section{REFERENCES}

[1] Brigade L F. London Community Risk Register [R] . London: Greater London Authority 2011.

[2] Team L R. London Community Risk Register [R]. London: Greater London Authority, 2011, 9.

[3] Cabinet Office. National Risk Register 2013 [R] . London: Cabinet Office, 2013.

[4] You Zhibin. The Main Experiences and Enlightenments of the United States Homeland Security Risk Management [J]. China Emergency Management, 2011, (4): 46-51.

[5] Zhou Yonggen, Qin Tingxin, Chen Rui. Studies on Standard System of Urban Risk Register of Grassroots Units [J]. Journal of Catastrophology, 2015, 30 (3): 140-149.

[6] Zhong Kaibin. The Main Methods and Experiences of Urban Risk Management in London [J]. Journal of China National School of Administration, 2011, (5): 113-117.

[7] Zhong Kaibin. Natural Hazard Risk Assessment in New York City: Measures and Experiences [J]. Chinese Public Administration, 2012, (10).

[8] Zheng H M, Guo-Liang E C, Engineer S, et al. Discussion on the Difference and Similarity of Some Terms Related to Fire Risk Assessment [J]. China Safety Science Journal, 2008, 18(6):75-79.

[9] Li Z, Engineer S, Prof, et al. Preliminary Probe into the Risk Assessment of Building Fire [J]. China Safety Science Journal, 2002, 12(2):30-34.

[10] Liu Lili. The Selective Method of Evaluation Index [J]. Journal of Hebei Institute of Architectural Engineering, 2004, 22(1): 134-136. 